\title{
Mekân-Zamansal Veri Madenciliği Yöntemi ile Otobüs Durak İhlallerinin Tespiti
}

\author{
Murat Taşyürek $^{1^{*}}$ \\ 1* Kayseri Üniversitesi, Mühendislik Mimarlık ve Tasarım Fakültesi, Bilgisayar Mühendisliği Bölümü, Kayseri, Türkiye, (ORCID: 0000-0001-5623-8577), \\ murattasyurek@kayseri.edu.tr
}

(2nd International Conference on Access to Recent Advances in Engineering and Digitalization (ARACONF)-10-12 March 2021)

(DOI: $10.31590 /$ ejosat.899717)

ATIF/REFERENCE: Taşyürek, M. (2021). Mekân-Zamansal Veri Madenciliği Yöntemi ile Otobüs Durak İhlallerinin Tespiti. Avrupa Bilim ve Teknoloji Dergisi, (24), 449-454.

\begin{abstract}
Öz
Otobüsler, nüfus yoğunluğunun fazla olduğu şehirlerde günlük hayatta sıklıkla kullanılan toplu taşımacılığının en önemli bileşenlerinden birisidir. Ulaşım için otobüsleri kullanan birçok insan otobüs durak ihlalinden dolayı günlük hayat planlamasında işe geç kalma veya eve geç kalma gibi problemler yaşamaktadır. Bu problemi yaşayan insanlar genellikle ilgili belediyenin çağrı merkezi veya web sitesi üzerinden durak numarası ve otobüs hattı gibi bilgiler ile şikâyet talebi oluşturur. İlgili belediye talebi inceleyerek gerçekte bir durak ihlali olup olmadığını tespit eder ve durak ihlali varsa ona göre aracı kullanan şoföre belirlenen kurallar çerçevesinde yaptırım uygular. Bu durum, durakta bekleyen gerçek bir vatandaş var ise ve ilgili vatandaş talep oluşturursa tespit edilmekte ve vatandaş tarafında da bir mağduriyet ve onun sonucunda ilgili belediye hizmetlerinden memnuniyetsizlik oluşmaktadır. $\mathrm{Bu}$ sorunların oluşmaması için otobüs durak ihlallerinin herhangi bir şikâyet talebi gelmeden tespit edilmesi ve durak ihlalinin tekrarlanmaması için gerekli işlemlerin yapılması önem arz etmektedir. Otobüs durak ihlalinin tespiti otobüste bulunan cihazların gönderdiği GPS sinyallerinin yanlış konumu göstermesi veya GPS sinyallerini düzenli olarak göndermemesinden kaynaklı zor bir problemdir. Literatürde otobüs durak ihlallerinin tespiti için veri madenciliği yöntemlerinden birliktelik kuralı tabanlı yöntemler kullanılmaktadır. Bu çalışmada, otobüs durak ihlallerinin tespiti için birliktelik kuralı tabanlı mekân-zamansal veri madenciliği yöntemi önerilmiştir. Önerilen yöntemin performansı gerçek veriler üzerinde birliktelik kuralı tabanlı mekânsal veri madenciliği yöntemi ile karşılaştırılmıştır. Bu çalışmada, Kayseri Büyükşehir Belediyesine ait 800 adet farklı otobüs hattının güzergâh verileri, bu hatlarda çalışan araçların mekân-zamansal GPS verileri ve 6482 adet otobüs durağının konum verileri kullanılmıştır. Deneysel sonuçlar, birliktelik kuralı tabanlı mekân-zamansal veri madenciliği yaklaşımının mekânsal veri madenciliği yaklaşımına göre daha tutarlı ve doğru sonuçlar verdiğini göstermiştir.
\end{abstract}

\section{Determination of Bus Station Violations with Spatial-Temporal Data Mining Method}

\begin{abstract}
Buses are one of the most important components of public transportation, which is frequently used in daily life in cities with high population density. Many people who use buses for transportation experience problems such as being late for work or being home late due to daily life planning due to bus station violations. People who have this problem usually create a complaint request through the relevant municipality's call center or website with information such as station and route number. The relevant municipality examines the request and determines whether there is a real violation of the station and if there is the station violation, it imposes sanctions on the driver who uses the vehicle according to the determined rules. This situation is determined if there is a real citizen waiting at the
\end{abstract}

*Sorumlu Yazar: murattasyurek@kayseri.edu.tr 
station and the relevant citizen creates a request, and there is a grievance on the part of the citizen and dissatisfaction with the relevant municipal services as a result. In order to prevent these problems, it is important that the bus station violations are detected before any complaint is requested and the necessary actions are taken to prevent the station violation from being repeated. Detection of bus station violations is a difficult problem due to the GPS signals sent by the devices on the bus showing the wrong location or not sending the GPS signals regularly. In the literature, association rule-based methods, one of the data mining methods, are used to detect bus station violations. In this study, an association rule-based spatio-temporal data mining method is proposed to detect bus station violations. The performance of the proposed method has been compared with the association rule based spatial data mining method on real data. In this study, route data of 800 different bus routes belonging to Kayseri Metropolitan Municipality, spatial-temporal GPS data of vehicles operating on these routes and location data of 6482 bus stations were used. Experimental results show that the association rule-based spatial-temporal data mining approach gives more consistent and accurate results than the spatial data mining approach.

Keywords: Spatial data, Spatio-temporal data mining, Bus station violation.

\section{Giriş}

Otobüsler, nüfus yoğunluğunun fazla olduğu şehirlerde günlük hayatta sıklıkla kullanılan toplu taşımacılığının en önemli bileşenlerinden birisidir (Taşyürek ve ark., 2020). Ulaşım için otobüsleri kullanan birçok insan otobüs durak ihlalinden dolayı günlük hayat planlamasından işe geç kalma veya eve geç kalma gibi problemler yaşamaktadır (Doğan ve ark., 2017). Toplu ulaşımda bekleme süresi, yolcuların algıladığı hizmet seviyesinin en önemli göstergelerinden biridir. Bu problemi yaşayan insanlar genellikle ilgili belediyenin çağrı merkezi veya web sitesi üzerinden durak numarası ve otobüs hattı gibi bilgiler ile şikâyet talebi oluşturur. İlgili belediye talebi inceleyerek gerçekte bir durak ihlali olup olmadığını tespit eder ve durak ihlali varsa ona göre aracı kullanan şoföre belirlenen kurallar çerçevesinde yaptırım uygular. $\mathrm{Bu}$ durum, durakta bekleyen gerçek bir vatandaş var ise ve ilgili vatandaş talep oluşturursa tespit edilmekte ve vatandaş tarafında da bir mağduriyet ve onun sonucunda ilgili belediye hizmetlerinden memnuniyetsizlik oluşmaktadır. $\mathrm{Bu}$ sorunların oluşmaması için otobüs durak ihlallerinin herhangi bir şikâyet talebi gelmeden tespit edilmesi ve durak ihlalinin tekrarlanmaması için gerekli işlemlerin yapılması önem arz etmektedir. Otobüs durak ihlalinin tespiti otobüste bulunan cihazların gönderdiği GPS sinyallerinin yanlış konumu göstermesi veya GPS sinyallerini düzenli olarak göndermemesinden kaynaklı zor bir problemdir.

Literatürde otobüs durak ihlallerinin tespiti için veri madenciliği yöntemlerinden birliktelik kuralı tabanlı yöntemler kullanılmaktadır (Kargupta, 2013; ve Samerei ark., 2020; Xydas ve ark., 2013). Veri madenciliği, büyük ölçekli veriler arasından değerli, ilginç ve anlamlı bilgileri çeşitli yöntem ve teknikler yordamıla tespit edilmesi olarak tanımlanır (Taşyürek ve ark., 2020). Veri madenciliği yöntemleri mekânsal, zamansal ve mekân-zamansal olarak kendi içerisinde gruplandırılabilir (Shekhar ve ark., 2008; Taşyürek ve ark., 2021). Mekânsal veri madenciliği konum (spatial) bilgilerini içeren veri kümelerine veri madenciliği yöntemleri uygulayarak konumlar ile ilgili faydalı bilgilerin ortaya çıkarılması olarak ifade edilir (Tasyurek ve ark., 2020). Zamansal veri madenciliği; zaman bilgileri içeren veri kümelerinde zamana bağlı veriler içerisinden anlamlı bilgiler çıkarmayı amaçlar (Mitsa, 2010). Mekân-zamansal veri madenciliği yöntemi ise konum ve zaman bilgilerini içeren veri kümelerinden veri madenciliği yöntemleri ile örüntü ve bilgi keşfetme olarak tanımlanır (Compieta ve ark., 2007). Bu çalışmada, otobüs durak ihlallerinin tespiti için birliktelik kuralı tabanlı mekân-zamansal veri madenciliği yöntemi önerilmiştir. $\mathrm{Bu}$ çalışmada önerilen sistemde Oracle veri tabanında gerçek veri olarak Kayseri Büyükşehir Belediyesi’ne (KBB) ait farklı otobüs hatlarının güzergâh verileri, bu hatlarda çalışan araçların mekân-zamansal GPS verileri ve otobüs duraklarının konum verileri kullanılmıştır.

$\mathrm{Bu}$ çalışmanın bundan sonraki bölümlerinde mekânzamansal veri madenciliği modeli tanıtılmış, otobüs GPS verilerinin mekân-zamansal olarak tutulduğu veri kümesinde durak ihlal tespiti tartışılmış ve sonuçlar bölümünde ise yapılan deney sonuçları ve uygulama paylaşılmıştır.

\section{Materyal ve Metot}

Bu çalışmada mekân-zamansal veri madenciliği yöntemi otobüs durak ihlallerinin tespiti için mekân ve zaman bilgilerini içeren gerçek veri kümesinde kullanılmıştır. $\mathrm{Bu}$ nedenle öncelikle mekân-zamansal veri madenciliği yöntemi tanıtılacak ve daha sonra ise bu yöntem ile otobüs durak ihlali tespit işlemleri tartışılacaktır.

\subsection{Mekân-zamansal Veri Madenciliği Yöntemi}

Mekânsal veri madenciliği konum (spatial) bilgilerini içeren veri kümelerine veri madenciliği yöntemleri uygulayarak konumlar ile ilgili faydalı bilgilerin ortaya çıkarılması olarak ifade edilir (Tasyurek ve ark., 2020). Zamansal veri madenciliği; zaman bilgileri içeren veri kümelerinde zamana bağlı veriler içerisinden anlamlı bilgiler çıkarması, mekân-zamansal veri madenciliği yöntemi ise konum ve zaman bilgilerini içeren veri kümelerinden veri madenciliği yöntemleri ile örüntü ve bilgi keşfetme olarak tanımlanır (Mitsa, 2010; Compieta ve ark., 2007). Mekânsal, zamansal ve mekân-zamansal veri madenciliği yöntemleri veri madenciliği yöntemleri üzerine kuruludur. En yaygın kullanılan veri madenciliği yöntemlerinden bir tanesi de birliktelik kuralıdır (Koperski ve ark., 1995). Olayların birlikte gerçekleşme durumlarını çözümleyen veri madenciliği yöntemi olarak tanımlanan birliktelik kuralı önceki verilerin analiz edilerek bu veriler içindeki birliktelik davranışlarının tespit edilmesi ile geleceğe yönelik çalışmalar yapılmasını destekleyen bir yöntemdir. Birliktelik kuralı tabanlı veri madenciliği yöntemi, sık geçen bütün öğelerin bulunması ve sık geçen bu öğelerden güçlü birliktelik kurallarının oluşturulması olmak üzere iki aşamadan oluşur. Birliktelik kuralının ilk aşaması için genellikle Apriori Algoritması kullanılır (Aflori ve ark., 2007). Algoritma ismini geçmiş verileri incelediğinden dolayı önceki anlamına gelen prior kelimesinden almaktadır (Yuan, 2017). Bu algoritmada özellikler ve veri, mantıksal (boolean) ilişki kuralları ile değerlendirilir (Yabing, 2013). Bu çalışmada Apriori algoritmasının mantıksal ilişki özelliği kullanılarak çözüm üretilmiş ve Bölüm 3.1 ve 3.2'de sunulmuştur. 


\section{Problem ve Çözümler}

Problem, KBB tarafından ulaşım sisteminde çalışan araçların güzergâh ihlallerinin tespit edilmesinde ortaya çıkmıştır. İlk olarak uygulamada, mekânsal veri madenciliği yöntemi birliktelik kuralı uygulanmış ve otobüs durak ihlali tespit edilmeye çalışılmıştır. Ancak, geliştirme aşamasında mekânsal veri madenciliği tabanlı sistemin özellikle otobüsün konum göndermediği durumlarda başarılı sonuçlar üretemediği görülmüştür. $\mathrm{Bu}$ noktada, konum verileri zaman bilgilerini içerdiğinden dolayı mekân-zamansal veri madenciliği yöntemi birliktelik kuralı tabanlı bir yöntem önerilmiş ve otobüs durak ihlalleri tespit edilmeye çalışılmıştır.

\subsection{Mekânsal Veri Madenciliği Yöntemi}

Yapılan incelemeler sonucunda otobüs hat numarası, hat güzergâhı, araç numarası, otobüs durak numarası ve durak konumu bilgilerinin normalizasyon işlemleri ile oracle veri tabanında mekânsal veri tablolarında tutulduğu tespit edilmiştir. Verilerin tutulduğu tablolar aşağıda gösterilmiş, tablo isimleri kalın renkli, birincil anahtar altı çizili, ikincil anahtarlar ise italik olarak sunulmuştur:

- OtoDurak (DurakNo, Adi, Geometri)

- Hat ( $\underline{\text { HatNo}}$, Adi, Geometri)

- $\operatorname{Arac}(\underline{\operatorname{AracN}}$, Plaka, Turu)

- AracHatKonum(AracNo, HatNo, Geometri, Tarih, BirOncekiKonumZamanFarki)

- OtoHatDurak(HatNo, DurakNo, SiraNo)

OtoDurak tablosu durak numarasının, durak adının ve durak konumunun geometri veri tipi olarak nokta türünde tutulduğu mekânsal bir tablodur. Hat tablosu, ulaşım sisteminde çalışan seferlerinin hat numarasının, güzergâh isminin ve güzergâh geometrik verisinin çizgi (line) formatında tutulduğu mekânsal tablodur. Arac tablosu ulaşım sisteminde çalışan araçların araç numarasının, plakasının ve aracın tür bilgisinin tutulduğu tablodur. AracHatKonum tablosu ulaşım sisteminde çalışan aracın hangi hatta çalıştığını bilgisinin mekânsal olarak tutulduğu en önemli tablodur. Bu tabloda araç numarası, hat numarası, aracın o an için nerede olduğunun konumu geometrik veri tipi olarak nokta formatında ve zaman bilgisi saniye bilgi detayıla tutulmaktadır. OtoHatDurak tablosu ise bir hat güzergâhında bulunan durak bilgilerinin tutulduğu tablodur. $\mathrm{Bu}$ tabloda hat numarası, durak numarası ve hattın sırası ile hangi duraklara uğrayacağının bilgisi sıra numarası ile tutulmaktadır.

Mekânsal veri madenciliği birliktelik yöntemi ile otobüs durak ihlali tespit edilirken öncelikte aracın çalıştığı hattın güzergâhında olması gerekmektedir. Şekil 1'de gösterilen sorgu aracın hatta olup olmadığını göstermektedir. Burada mekânsal veri madenciliği yöntemlerinden olan birliktelik kuralının mantıksal (boolean) özelliği kullanılmaktadır. Hat üzerinde çalışan aracın konumu hatta 30 metre mesafeden daha yakınsa aracın o hatta çalıştığ kabul edilmektedir yani bu durumda araç ve hat birliktedir. $\mathrm{Bu}$ kural oracle veri tabanın mekânsal sorgularından olan Şekil 1'de gösterilen "SDO_GEOM.WITHIN_DISTANCE" mantıksal fonksiyonu ile sağlanmaktadır. Şekil 1'de bulunan sorguda geçen "PARAM_ARACNO" parametresi güzergâh ihlali tespiti için incelenen aracın araç numarasını ifade etmektedir.

İncelenen araç otobüs güzergâhında çalışıyor ise bu durumda aracın duraklara uğrayıp uğramadığının tespit edilmesi gerekmektedir. Bu durumda Şekil 2'de bulunan sorgu ile tespit edilmektedir. Bu sorguda da mekânsal veri madenciliği yöntemi mantıksal birliktelik kuralı uygulanmaktadır. Hatta çalışan araç hatta bulunan duraklara 200 metreden daha yakın mesafede bulunmuş ise bu araç duraklara uğradı olarak kabul edilmektedir. Burada mesafenin 200 metre seçilmesine KBB ile yapılan görüşmeler neticesinde karar verilmiştir. KBB tarafından kullanılan ulaşım sisteminde araçlar 7 saniye aralıklara konum göndermektedir (Taşyürek ve ark., 2020). Bu da yaklaşık olarak durağın 100 metre öncesi veya 100 metre sonrasına gelebilmektedir ve bu durumları durak ihlali tespit etmemesi için 200 metre eşik değer olarak seçilmiştir. Bir araç durağa 200 metreden daha yakın konumda bulunmuş ise araç durağa uğramıştır ve mekânsal veri madenciliği açısından ise araç ile durak birliktedir. Sistemde incelenen aracın uğraması gereken bütün duraklardan uğramış olduğu duraklar çıkartıldığında aracın uğramadığı duraklar tespit edilmektedir.

\subsection{Mekân-zamansal Veri Madenciliği Yöntemi}

Mekânsal veri madenciliği yöntemi ile önerilen çözüm, ulaşım sisteminde çalışan araçların düzenli olarak konum gönderdiğinde başarılı sonuçlar üretmesine rağmen kırsal kesim gibi arazi şartlarının uygun olmadığı yerlerde araçların konum göndermediğinde, anlık konum kaybında veya hava şartlarından

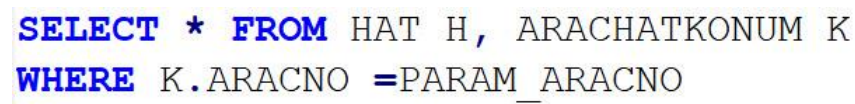

Şekil 1 Araç Hat Sorgusu

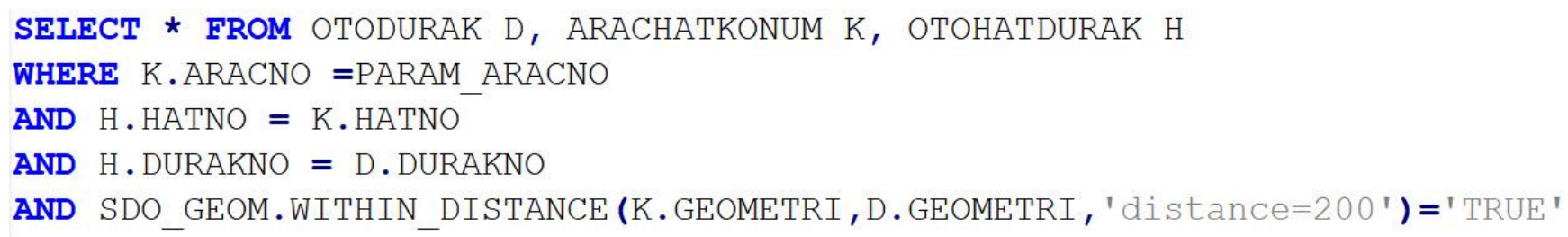


kaynaklı konum göndereme durumunda istenilen sonuçları elde edilememiştir. Örneğin araç iki dakika gibi bir zaman aralığında konum göndermediğinde mekânsal veri madenciliği yöntemi öncelikle aracın uğradığı durakları tespit edecek daha sonrada uğraması gereken duraklardan uğradı durakları çıkararak uğramadığı durakları tespit edecektir. Fakat iki dakika boyunca konum göndermediği ancak gerçekte araç tarafindan uğranan duraklar bu yöntemde aracın uğramadığ duraklar olarak gösterilmektedir. Bu sorunun üstesinden gelmek için dolayısı ile araç konum göndermediğinde durak ihlali olarak algılanmasının önüne geçmek için mekân-zamansal veri madenciliği birliktelik kuralı tabanlı bir çözüm önerilmiştir. Mekân-zamansal veri madenciliği yöntemi mantıksal birliktelik kuralı ulaşım sistemine uygulandığı zaman aracın mekânsal ve zamansal veri madenciliği yönteminin kurallarını aynı anda sağlaması gerekmektedir. KBB ile yapılan görüşmeler neticesinde araçlar 7 saniye aralıkla konum gönderdiğinden ve aracın durağa uğramış olarak kabul edilmesi için durağa 200 metre mesafeden daha yakın olması gerektiğinden dolayı zamansal veri madenciliği şartı 30 saniye olarak alınmıştır. Mekân-zamansal veri madenciliği yönteminde durak ihlalinin tespiti için aracın göndermiş olduğu konumların zaman farkları en az 30 saniye olmalıdır. Diğer bir ifade ile aracın göndermiş olduğu iki konum arasındaki zaman farkı 30 saniyeden daha fazla ise bu araçta durak ihlali aranmamalıdır. Mekân-zamansal veri madenciliği yöntemi açısından aracın göndermiş olduğu bütün konumlar arasındaki zamansal mesafe 30 saniyeden daha küçük ise bu konumlar zamansal açıdan birliktedir. Zamansal birlikteliği gösteren bu kural Şekil 3 'te gösterilmiştir.

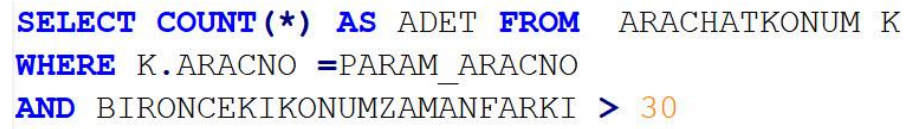

\section{Şekil 4 Zamansal Birliktelik Sorgusu}

Mekân-zamansal veri madenciliği yönteminde öncelikle Şekil 3 'te bulunan sorgu çalıştırılır. Bu sorguda dönen değerin sıfır olması gerekmektedir. Değer sıfır döndügünde mekânzamansal veri madenciliği açısından tüm konumlar zamansal açıdan birliktedir. Bu kural sağlandıktan sonra Şekil 1 ve 2'de bulunan konumların mekânsal olarak birlikte olduğunu gösteren sorgula çalıştırılır. Bu üç sorgu sayesinde mekân-zamansal veri madenciliği yöntemi ile otobüs durak ihlali tespit edilir.

\section{Araştırma Sonuçları ve Tartışma}

Bu çalışmada KBB'den alınan gerçek mekânsal ulaşım verileri kullanılmıştır. KBB'ye ait verilerin özet bilgisi Tablo 1 'de gösterilmiştir. Tablo 1'de KBB'ye ait 800 adet farklı otobüs hat güzergâhının, güzergâhın geçtiği durakların ve bu güzergâhta çalışan araçların mekân-zamansal veriler hakkında bilgi sunulmuştur. KBB tarafından 2020 yılı aralık ayına ait veriler paylaşılmıştır. $\mathrm{Bu}$ zaman içerisinde veri tabanında araçların konum geçmişini gösteren yaklaşık olarak 82.000.000 kayıt bulunmaktadır.

Tablo 1. KBB Mekânsal Veriler

\begin{tabular}{l|l|l}
\hline Tablo Adı & Geometrik Veri Tipi & Kayıt Sayısı \\
\hline OtoDurak & Nokta & 6.482 \\
\hline Hat & Çizgi & 800 \\
\hline AracHatKonum & Nokta & 82.000 .000 \\
\hline OtoHatDurak & - & 53.317 \\
\hline Arac & - & 1.172 \\
\hline
\end{tabular}

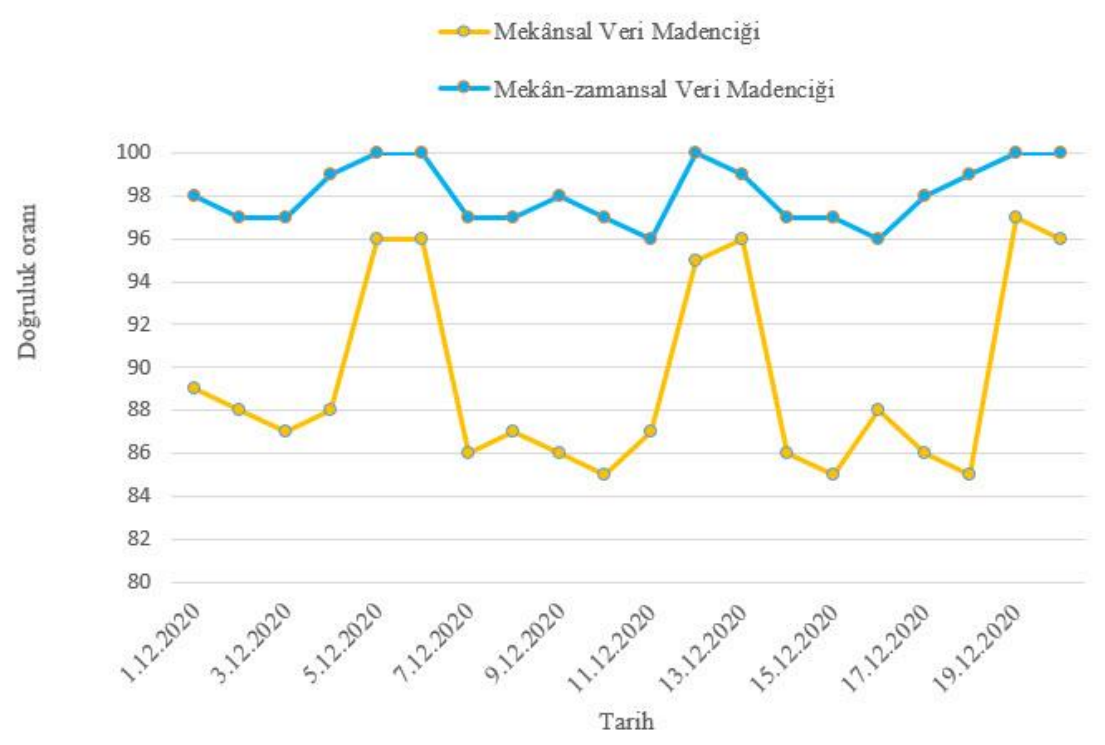

Şekil 3 Yöntemlerin Doğruluk Oranı 
Bu çalışmada gerçekleştirilen deneyler Intel Xenon E5-2660 V3 $2.30 \mathrm{GHz}$ (4 Core) 16 GB Ram 500 GB Sata disk özelliklerine sahip ve Windows Server 2016 sunucu işletim sistemi kurulu olan bir bilgisayar ortamında çalıştırılmıştır.

\subsection{Deneysel Sonuçlar}

Mekânsal veri madenciliği yöntemi ve mekân-zamansal veri madenciliği yöntemi ile oluşturulan çözümlerinin sonuçları karşılaştırmak için 2020 yılı aralık aynının ilk yirmi günü için yaklaşımların durak ihlali olarak tespit etmiş olduğu bütün seferler incelenmiştir. Her iki yöntem içinde durak ihlali olarak tespit ettiği seferlerin gerçekten ihlal olup olmadığ üzerinde aracın göndermiş olduğu konumlar kontrol edilerek araştırılmıştır. Yöntemlerin doğruluk oranı Şekil 4'te verilmektedir. Şekilde yöntemlerin doğru tespit ettiği sefer sayısının toplam tespit sefer sayına oranı doğruluk oranı olarak belirtilmiştir.

Şekil 4'te görüldüğü üzere mekân-zamansal veri madenciliği yöntemi mekânsal veri madenciliği yöntemine göre daha başarı sonuçlar üretmiştir. Mekân-zamansal veri madenciliği yöntemi zamansal birliktelik incelediğinden dolayı araçların konum göndermediği durumları incelememiş düzenli olarak konum gönderdiği durumları inclenmiş ve bu yüzden durak ihlallerini daha başarılı olarak tespit etmiştir. Mekânsal veri madenciliği yöntemi araçların GPS verilerini göndermediği durumlarda zamansal birlikteliği dikkate almadığından dolayı bu seferleri durak ihlali olarak tespit etmektedir. Deneysel sonuçlar incelendiğinde bazı günlerde yaklaşımların başarı oranlarının birbirlerine yakın olduğu gözlenmiştir. Bunun sebebi ise covid19 salgının yayılmasını önlemek için sokağa çıkma yasağı ilan edilmesinden dolayı o gün düzenlenen sefer sayılarının az olmasidir.

\subsection{Durak İhlal Tespit Uygulaması}

Önerilen mekân-zamansal veri madenciliği tabanlı yaklaşım KBB'nin kurumsal portal sayfasında aktif olarak kullanılmaktadır. İlgili sayfaya kurum içerisinde yetkilendirilen personeller erişebilmektedir. Şekil 5'te KBB tarafından kullanılan ve sistem tarafından tespit edilen durak ihlali gösterilmiştir. Şekil 5 'te görüldüğü üzere araç tarafından düzenli olarak GPS verileri gönderilmektedir. Fakat araç ana duraktan hareket etmesi gerekirken ana durağa uğramadan direk sefere başlamıştır. Önerilen sisteme aracın uğramadığı durak mavi renkle çizili çember içerisinde gösterilmektedir.

\section{Sonuç}

Mekânsal ve mekân-zamansal veri madenciliği yöntemi günümüzde yaygın olarak kullanılmaktadır. Konum verilerinin zamanla ilişkisinin olduğu veya zaman göre değiştiği durumlarda mekân-zamansal veri madenciliği yöntemi mekânsal veri madenciliği yöntemine göre daha başarı sonuçlar üretmektedir. Bu çalışmada, ulaşım sistemine çalışan araçların göndermiş olduğu GPS verilerinin mekân ve zaman bilgileri ile birlikte tutulduğu mekânsal veri tabanında otobüs durak ihlallerinin mekân-zamansal veri madenciliği yöntemi ile tespit edilmesi için sistem önerilmiştir. Önerilen mekân-zamansal veri madenciliği tabanlı sistemin çözümünün performansı mekânsal veri madenciliği tabanlı sistemin çözümünün performansı ile KBB'den alınan gerçek veriler kullanılarak karşılaştırılmıştır. Deneysel sonuçlar mekân-zamansal veri madenciliği yöntemi ile geliştirilerek önerilen çözümün mekânsal veri madenciliği yöntemi ile geliştirilen çözüme göre daha iyi sonuçlar ürettiğini göstermiştir.

\section{Teşekkür}

$\mathrm{Bu}$ çalışma kapsamında kullanılan ulaşım sistemine ait otobüs hatlarının ve durakların mekânsal konum verilerini ve ulaşım araçların mekân-zamansal GPS verilerini paylaştığı için Kayseri Büyükşehir Belediyesi'ne (KBB) teşekkürlerimi sunarım.

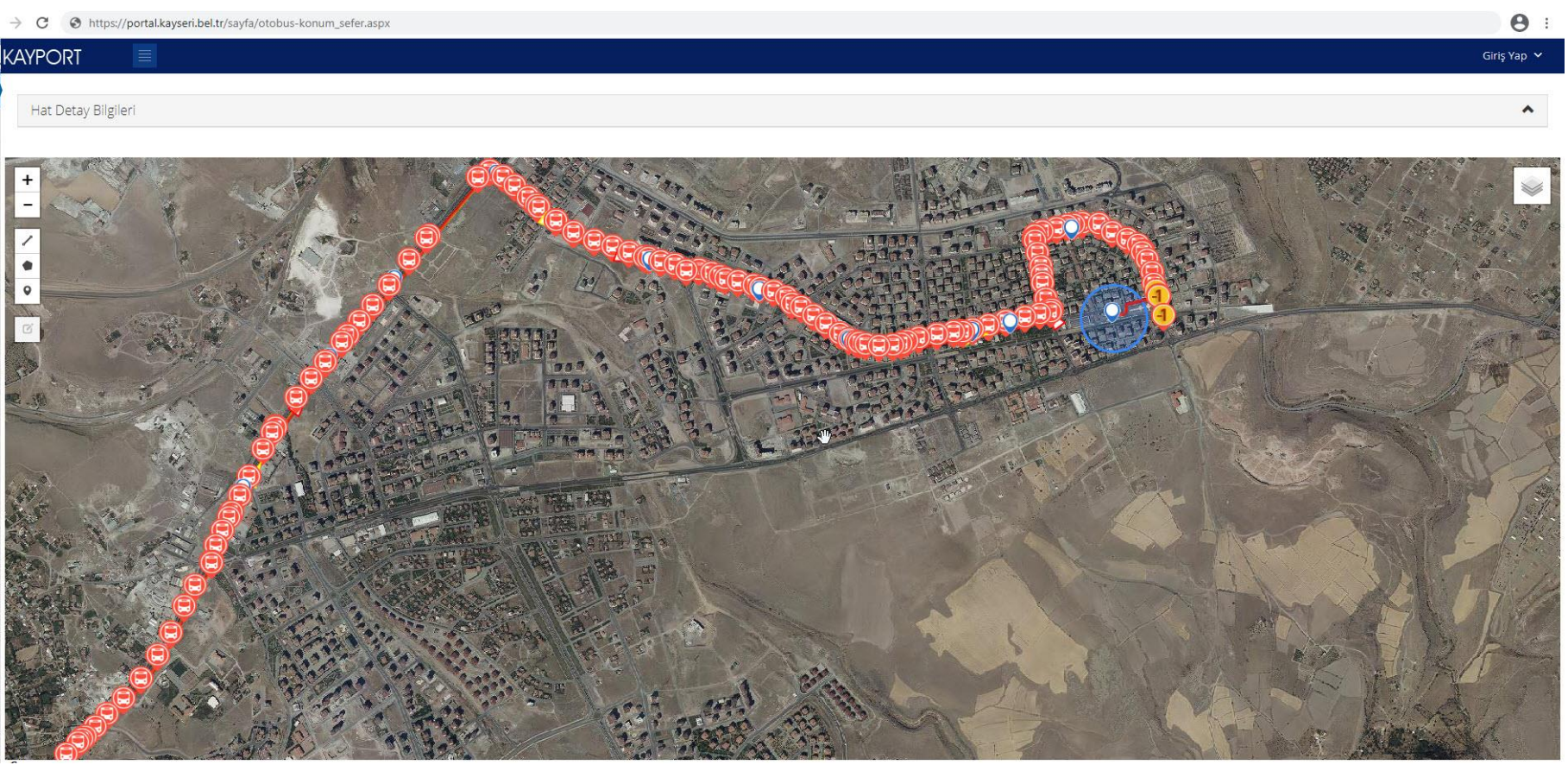




\section{Kaynakça}

Aflori, C., \& Craus, M. (2007). Grid implementation of the Apriori algorithm. Advances in engineering software, 38(5), 295-300.

Compieta, P., Di Martino, S., Bertolotto, M., Ferrucci, F., \& Kechadi, T. (2007). Exploratory spatio-temporal data mining and visualization. Journal of Visual Languages \& Computing, 18(3), 255-279.

Doğan, G., Özuysal, M. (2017). Toplu Ulaşımda Bekleme Süresini Etkileyen Faktörlerin İncelenmesi: Güvenilirlik, Yolcu Bilgilendirme Sistemi ve Fiziksel Koşullar. Teknik Dergi, 28 (3), 7927-7954. DOI: 10.18400/tekderg.307513

Kargupta, H. (2013). U.S. Patent No. 8,478,514. Washington, DC: U.S. Patent and Trademark Office.

Koperski, K., \& Han, J. (1995, August). Discovery of spatial association rules in geographic information databases. In International Symposium on Spatial Databases (pp. 47-66). Springer, Berlin, Heidelberg.

Mitsa, T. (2010). Temporal data mining. CRC Press.

Samerei, S. A., Aghabayk, K., Mohammadi, A., \& Shiwakoti, N. (2020). Data mining approach to model bus crash severity in Australia. Journal of Safety Research.

Shekhar, S., Vatsavai, R. R., \& Celik, M. (2008). Spatial and spatiotemporal data mining: Recent advances. Data mining: next generation challenges and future directions, 1-34.
Tasyurek, M., \& Celik, M. (2020). RNN-GWR: A geographically weighted regression approach for frequently updated data. Neurocomputing, 399, 258-270.

Taşyürek, M., Çelik, M. (2020). Akıllı Durak Sistemindeki Araç Seyahat Sürelerinin Birleşik Yapay Sinir Ağları Kullanarak Tahmini. Avrupa Bilim ve Teknoloji Dergisi, Ejosat Special Issue 2020 (ARACONF), 72-79. DOI: 10.31590/ejosat.araconf 10

Taşyürek, M. \& Çelik, M. (2020). Hava Sıcaklık Değerlerinin Coğrafi ve Rakım Ağırlıklı Regresyon Yöntemi ile Tahmin Edilmesi. Avrupa Bilim ve Teknoloji Dergisi, Ejosat Special Issue 2020 (HORA), 81-86. DOI: 10.31590/ejosat.779074

Taşyürek, M., \& Çelik, M. (2021). FastGTWR: Hızlı coğrafi ve zamansal ağırlıklı regresyon yaklaşımı. Gazi Üniversitesi Mühendislik Mimarlık Fakültesi Dergisi, 36(2), 715-726.

Xydas, S., Marmaras, C. E., Cipcigan, L. M., Hassan, A. S., \& Jenkins, N. (2013). Electric vehicle load forecasting using data mining methods.

Yabing, J. (2013). Research of an improved apriori algorithm in data mining association rules. International Journal of Computer and Communication Engineering, 2(1), 25.

Yuan, X. (2017, March). An improved Apriori algorithm for mining association rules. In AIP conference proceedings (Vol. 1820, No. 1, p. 080005). AIP Publishing LLC. 